\title{
MIRACLE MEDICINE FOR PREVENTION OF MIGRAINE ATTACK: METFORMIN.
}

1. MBBS, M.Phil, Ph.D

Associate Professor Pharmacology Dow International Medical College.

2. MBBS, MCPS

Physician

Sindh Services Hospital Karachi.

3. MBBS, M.Phil

Lecturer Anatomy

KMDC.

4. MBBS, M.Phil

Lecturer Anatomy

KMDC

5. MBBS, MPhil (Biochemistry)

Assistant Professor Biochemistry

DMC.

6. MBBS, Ph.D

Professor Pharmacology

DIMC

Correspondence Address:

Dr. Fatima Rizvi

A342, Block 1, Gulshn e lqbal,

Karachi.

fatima.rizvi@duhs.edu.pk

Article received on:

02/07/2019

Accepted for publication:

20/01/2020
Fatima Rizvi', Abid Sheikh², Hira Ahmed ${ }^{3}$, Shazia Fahmi ${ }^{4}$, Zia Ikramuddin ${ }^{5}$, Mahayrukh Asif ${ }^{6}$

ABSTRACT... Objectives: In search of effective and economical option for prophylaxis of Migraine evaluating the prophylactic role of Metformin in migraine. Study Design: Single blind placebo controlled trial. Setting: Department of Pharmacology BMSI, JPMC, in collaboration with Sindh services Hospital Karachi. Period: April 2017 - August 2018. Material \& Methods: A total 105 patients with diagnosed migraine were included in this trial. Total patients were equally divided into 3 groups designated Groups A, B, and C that were representative of Placebo, Metformin and Propranolol groups respectively. Total study duration was 6 months, which were equally divided into 2 phases. First 3 month phase was baseline period and later one was treatment period. The primary parameters for evaluating the prophylactic role of Metformin in Migraine were Migraine integral Burden scale (MIBS), HIT-6, MIDAS, MPQ-5, frequency of migraine attack per month. Results: At baseline there were statistically non-significant differences found for MIBS $(F(2,102)=0.346, p=0.708)$, $\operatorname{MIDS}(F(2,102)=0.248, p=0.781)$, MPQ $(F(2,102)=0.188, p=0.828)$ and severity of headache $(F(2,102)=0.247, p=0.782)$ among all treated groups. But at final follow up there was highly significant difference were found among all treated groups for all parameters. Pairwise comparison showed significant differences between group $A$ and $B$ and group $A$ and $C$ was recorded for all parameters. Nevertheless there was no difference seen in group $B$ and $C$ (mean difference $(M D)=-0.171$ $\pm 0.149, p=0.485),(M D=-0.143 \pm 0.132, p=0.526),(M D=-2.057 \pm 0.301, p<0.001),(M D=$ $-0.314 \pm 0.360, p=0.658),(M D=-0.514 \pm 0.288, p=0.179),(M D=0.00 \pm 0.149, p=1.00)$ for MIBS, migraine frequency, HIT-6, MIDS, MRQ, headache severity respectively. Conclusion: This study demonstrated that Metformin is valuable, safer and economical option for preventive measure of Migraine.

Key words: $\quad$ HIT-6, MIBS, MPQ-5, MIDAS, Metformin, Migraine.

Article Citation: Rizvi F, Sheikh A, Ahmed H, Fahmi S, Ikramuddin Z, Asif M. Miracle medicine for prevention of migraine attack: Metformin. Professional Med $\mathrm{J}$ 2020; 27(4):812-819. DOI: 10.29309/TPMJ/2020.27.04.3892

\section{INTRODUCTION}

Migraines are a leading cause of disability and suffering worldwide. Migraine is an exceptionally predominant neurological sickness, influencing 39 million of either sex in the U.S and 1 billion around the world. It is the third most pervasive and sixth most handicapping ailment worldwide. It is best depicted as a direct to extreme throbbing cerebral pain enduring 4- 72 hours and is frequently connected with queasiness, retching, photophobia along with phonophobia. ${ }^{1}$

Headache cerebral pain sufferers frequently encounter generous reductions in work productivity and capability, diminished quality of life for the patient and high money related encumbrances on people and health care. ${ }^{2}$ Clearly, successful prophylactic treatment for the avoidance of headache migraines could significantly diminish the cost of human services for these patients and enhance their personal satisfaction. $^{3}$

The objectives of treatment for patients requiring prophylactic treatment are to diminish the recurrence, length and seriousness of assaults, lessen handicap and enable intense treatment to work all the more successfully. ${ }^{4}$

Migraine pain is related with the enactment and refinement of particular receptors associated with torment advancing pathways. Metformin, 
which is a broadly accessible, all around endured against diabetic medicine, can down regulate pain advancing pathways. Metformin has shown positive outcomes in creature models of migraine in the research studies. ${ }^{5}$

AMPK's distinctive placement as a negative regulator of mTORC1-mediated, activitydependent protein synthesis and other signaling pathways associated with chronic pain make this kinase an optimal target for harnessing an endogenous regulatory mechanism that can dampen the excitability and sensitization of nociceptors. ${ }^{6}$

Metformin (dimethyl biguanide) is a synthetic byproduct of guanidine, isolated from the extracts about Galega officinalis (a plant that have prominent antidiabetic effect). Since its discovery, metformin represents a worldwide milestone within therapy about sufferers with type II diabetes mellitus. ${ }^{7}$ Recent proof in humans indicates novel pleiotropic actions of Metformin that span from its consolidated role in Type 2 Diabetes management up to varied regulative properties, as well as cardio- and nephro-protection, additionally as antioxidants, antiproliferative, antifibrotic effects. ${ }^{8}$ Additionally its favorable effects on different neurodegenerative disorders ${ }^{9}$, neuroplasticity and management of chronic or pathological pain have also demonstrated by different researchers. ${ }^{10,11}$

Thus aim of this therapy is evaluate the effective economical and safer option for prophylaxis of migraine.

\section{METHODOLOGY}

This interventional trial conduced in department of Pharmacology of BMSI in alliance with department of Medicine Sindh services hospital Karachi. Total duration of study was 16 months (April 2017 - August 2018) with individual study duration was 6 months, out of which first three months were baseline period and 3 months were of actual study period. Total 105 patients age ranges between 20 - 65 years of either sex with diagnosed migraine with or without aura for $>1$ year according to the International Classification of Headache Disorders were included in our study and equally divided into three groups designated Placebo (twice daily per orally for 3 months), Metformin (assigned to receive $500 \mathrm{mg}$ per orally twice daily for 3 months) and Propranolol (80-160mg / day for 3 months). Note: Acute management for Migraine attack was allowed during study SOS.

Our Exclusion Criteria were: 1. diagnosis of diabetes mellitus or polycystic ovarian syndrome, 2. Overuse of acute migraine, 3. Failure to respond to 3 or more previous preventive drug treatments, 4. change in dose of migraine-preventive medication within 2 months of beginning the baseline diary phase, 5. Significant somatic or psychiatric disease, 6. known alcohol or other substance abuse, 7. Pregnant or breastfeeding. The impacts on quality of life of migraine sufferer were evaluated by MIBS-4, MIDS, HIT-6, MPQ, Migraine frequency and Severity of headache.

The Migraine Interictal Burden Scale (MIBS) measures interictal migraine-related burden in 4 domains: work or school impairment, family and social life impairment, difficulty in fulfilling commitments, and cognitive \& emotional distress. ${ }^{12,13}$

Headache impact test (HIT-6) is a reliable tool for episodic and chronic migraine to discriminate the effect of headache. ${ }^{14}$

Migraine Prevention Questionnaire 5 (MPQ5) is primarily instrumental tool to assess the effectiveness of preventive measures used in migraines to be given preventive medication used in the primary care. It includes categorical questions containing four domains: 1) frequency and severity of headache 2) use of acute medication 3) impairment; 4) interracial headache burden. ${ }^{15}$

The Migraine Disability Assessment (MIDAS) is a simple score to or determining the effect of migraine headache on the capacity of a person to operate in workplace and social circumstances. Time to time is pursued to evaluate the reaction of a person to the development of the disease. The 
validity of MIDAS score comprising of its five items was compared to 90 days record used to assess disability from headache. The values of mean and median for the MIDAS score in migraine cases were similar to equivalent diary measures. ${ }^{16}$

Frequency and severity of migraine attack was evaluated per month by Headache dairy. ${ }^{17}$

SPSS version 22 was used for data analyses. Data is presented in the form of mean and percentages. The comparison of proportions was done by Pearson's chi-square test. The difference between groups was assessed using one wayANOVA. A p-value of 0.05 or less was considered as statistically significant and highly significant at 0.01 or less.

\section{RESULTS}

Comparison of demographic characteristics shows non-significant difference among all treated groups. As there were non-significant differences among groups for Mean age ( $F$ $(2,102)=0.334, p=0.717)$, for Gender $(x 2(2)=$ 2.059, $p=0.357)$, family history of migraine (x2 $(2)=1.487, p=0.476)$, Marital status ( $x 2$ $(2)=0.090, p=0.956)$, Duration of migraine attack (in hour) $(F(2,102)=0.334, p=0.717)$, severity of headache $(F(2,102)=0.247, p=0.782)$ and severity of Migraine attack $(F(2,102), 0.247, p=0.782)$.

Comparison of MIBS-4 showed statistically no significant difference between groups at baseline as determined by one-way ANOVA (F $(2,102)$ $=0.346, p=0.708)$. At 3rd month comparison of MIBS -4 among all treated groups revealed statistically highly significant differences ( $F$ $(2,102)=271.509, \mathrm{p}<0.001)$. On post hoc analysis pairwise comparison showed there were statistically highly significant differences between Group $\mathrm{A}$ and $\mathrm{B}$ (mean difference = $3.086 \pm 0.149, p<0.001)$ as well as between Group A and C (mean difference $=2.914 \pm 0.149$, $p<0.001)$. However there was statistically no significant difference between Group B and C (mean difference $=-0.171 \pm 0.149, p=0.485$ ). As depicted in Table-l.

Comparison of MIDs at baseline among all treated groups showed non-significant differences ( $F$ $(2,102)=0.248, p=0.781)$. Post hoc comparison of MIDS at baseline showed non-significant differences between Group A and B (mean difference $=-0.200 \pm 0.285, p=0.763)$, Group $A$ and $C$ (mean difference $=-0.086 \pm 0.285$, $\mathrm{p}=0.951$ ) and Group B and C (mean difference $=$ $0.114 \pm 0.285, p=0.915)$. At 3rd month post hoc comparison showed statistically highly significant differences among Group A and B (mean difference $=11.829 \pm 0.360, p<0.001$ ) and Between Group $\mathrm{A}$ and $\mathrm{C}$ (mean difference = $11.514 \pm 0.360, p<0.001)$. Conversely showed statistically non-significant difference among Group B and C (mean difference $=-0.314 \pm 0.360$, $\mathrm{p}=0.658)$. As depicted in Table-II.

Comparison of MPQ at baseline among all treated groups showed statistically non-significant difference $(F(2,102)=0.188, p=0.828)$. Post hoc comparison showed at baseline there were statistically non-significant differences among Group A and B (mean difference $=0.200 \pm 0.327$, $\mathrm{p}=0.814$ ), Group $\mathrm{A}$ and $\mathrm{C}$ (mean difference = $0.114 \pm 0.327, p=0.935$ ) and Group B and C (mean difference $=-0.086 \pm 0.327, p=0.963$ ). Finally at $3^{\text {rd }}$ month highly significant differences were found between Group A and B (mean difference $=11.914 \pm 0.288, p<0.001)$ and between Group $A$ and $C$ (mean difference $=11.40 \pm 0.288, p<0.001$ ) with no significant difference was found between Group B and C (mean difference $=-0.514 \pm$ $0.288, p=0.179$ ). As depicted in Table-III.

Comparison of severity of headache among all treated groups at baseline showed no significant difference $(F(2,102)=0.247, p=0.782)$. Post hoc analysis of severity of headache at baseline showed that there were statistically no significant differences among Group A and B (mean difference $=-0.029 \pm 0.169, p=0.984)$, Group $A$ and $C$ (mean difference $=-0.114 \pm 0.169, p=$ 0.778 ) as well as between Group B and C (mean difference $=-0.086 \pm 0.169, p=0.868$ ). Finally at $3^{\text {rd }}$ month highly significant differences were found among Group A and B (mean difference $=2.257 \pm 0.149, p<0.001)$ and Between Group A and $C$ (mean difference 2.257 $\pm 0.149, p<0.001$ ). However non-significant difference was found 
among Group B and C (mean difference = $0.00 \pm 0.149, p=1.00)$. As depicted in Table-IV.

Comparison of Migraine frequency among all treated groups revealed that at baseline there was statistically no significant difference ( $F$ $(2,102)=3.018, p=0.053)$. Post hoc analysis at baseline showed that there were statistically no significant differences for Frequency of Migraine among Group A and B (mean difference $=-0.286$, $p=0.1732$ ), Group A and C (mean difference
$=-0.371 \pm 0.158, p=0.054)$ and Group $B$ and $C$ (mean difference $=-0.086 \pm 0.158, p=0.851$ ). At $3^{\text {rd }}$ month post hoc comparison revealed statistically highly significant differences among Group A and B (mean difference $=3.229 \pm 0.132$, $\mathrm{p}<0.001$ ) and Group A and C (mean difference= $3.086 \pm 0.132, p<0.001) \quad$ with non-significant difference among Group B and C (mean difference $=-0.143 \pm 0.132, p=0.526)$. As depicted in Table-V.

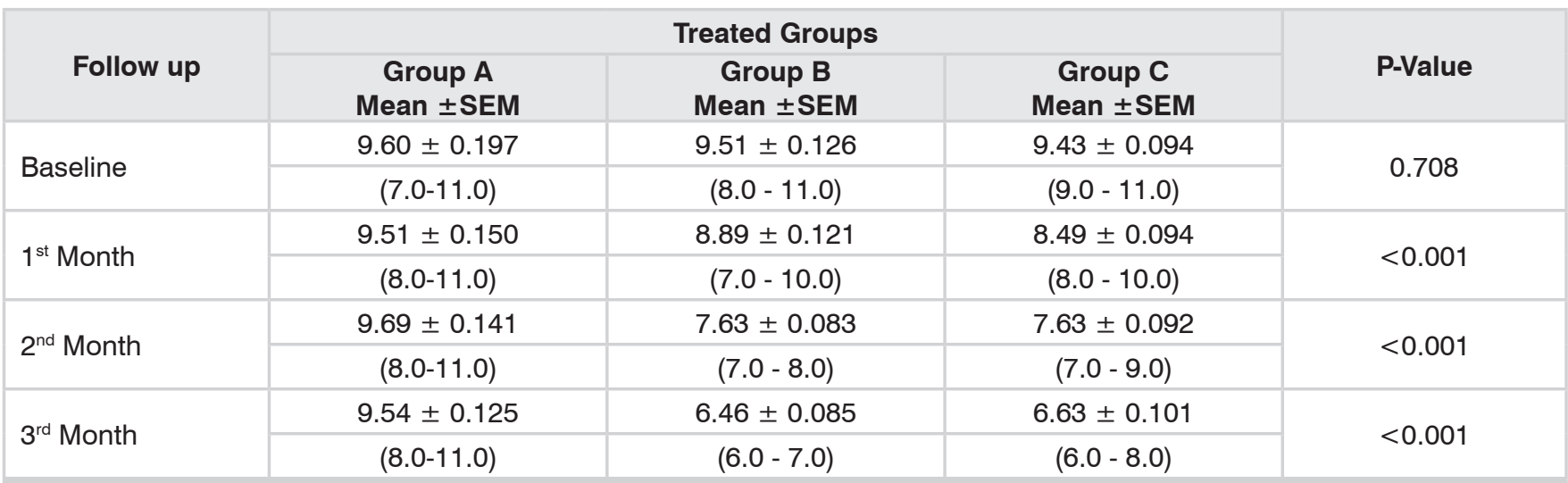

Table-I. Comparison of MIBS-4 among all treated Groups

\begin{tabular}{|c|c|c|c|c|}
\hline \multirow[b]{2}{*}{ Follow Up } & \multicolumn{3}{|c|}{ Treated Groups } & \multirow[b]{2}{*}{ P-Value } \\
\hline & $\begin{array}{c}\text { Group A } \\
\text { Mean } \pm \text { SEM }\end{array}$ & $\begin{array}{c}\text { Group B } \\
\text { Mean } \pm \text { SEM }\end{array}$ & $\begin{array}{c}\text { Group C } \\
\text { Mean } \pm \text { SEM }\end{array}$ & \\
\hline \multirow{2}{*}{ Baseline } & $22.83 \pm 0.237$ & $23.03 \pm 0.190$ & $22.91 \pm 0.171$ & \multirow{2}{*}{0.781} \\
\hline & $(21.0-26.0)$ & $(21.0-26.0)$ & $(21.0-25.0)$ & \\
\hline $1^{\text {st }}$ Month & $23.34 \pm 0.217$ & $15.74 \pm 0.144$ & $20.66 \pm 0.183$ & $<0.001$ \\
\hline $2^{\text {nd }}$ Month & $(21.0-34.0)$ & $(43.0-47.0)$ & $(14.0-18.0)$ & $<0.001$ \\
\hline \multirow{2}{*}{$3^{\text {rd }}$ Month } & $23.63 \pm 0.374$ & $11.80 \pm 0.107$ & $12.11 \pm 0.208$ & \multirow{2}{*}{$<0.001$} \\
\hline & $(21.0-34.0)$ & $(11.0-13.0)$ & $(10.0-14.0)$ & \\
\hline \multicolumn{5}{|c|}{ Table-II. Comparison of MIDS among all treated Groups } \\
\hline Follow up & \multicolumn{3}{|c|}{ Treated Groups } & P-Value \\
\hline \multirow{2}{*}{ Baseline } & $30.3 \pm 0.297$ & $29.83 \pm 0.190$ & $29.91 \pm 0.190$ & \multirow{2}{*}{0.828} \\
\hline & (23.0-33.0) & $(28.0-32.0)$ & $(28.0-32.0)$ & \\
\hline \multirow{2}{*}{$1^{\text {st }}$ Month } & $30.09 \pm 0.202$ & $25.74 \pm 0.180$ & $25.94 \pm 0.196$ & \multirow{2}{*}{$<0.001$} \\
\hline & (28.0-32.0) & $(23.0-27.0)$ & $(23.0-28.0)$ & \\
\hline \multirow{2}{*}{$2^{\text {nd }}$ Month } & $30.57 \pm 0.233$ & $21.57 \pm 0.210$ & $22.09 \pm 0.150$ & \multirow{2}{*}{$<0.001$} \\
\hline & $(28.0-33.0)$ & $(18.0-23.0)$ & $(20.0-24.0)$ & \\
\hline \multirow{2}{*}{$3^{\text {rd }}$ Month } & $30.37 \pm 0.253$ & $18.46 \pm 0.189$ & $18.97 \pm 0.156$ & \multirow{2}{*}{$<0.001$} \\
\hline & (28.0-33.0) & $(16.0-22.0)$ & $(18.0-21.0)$ & \\
\hline
\end{tabular}




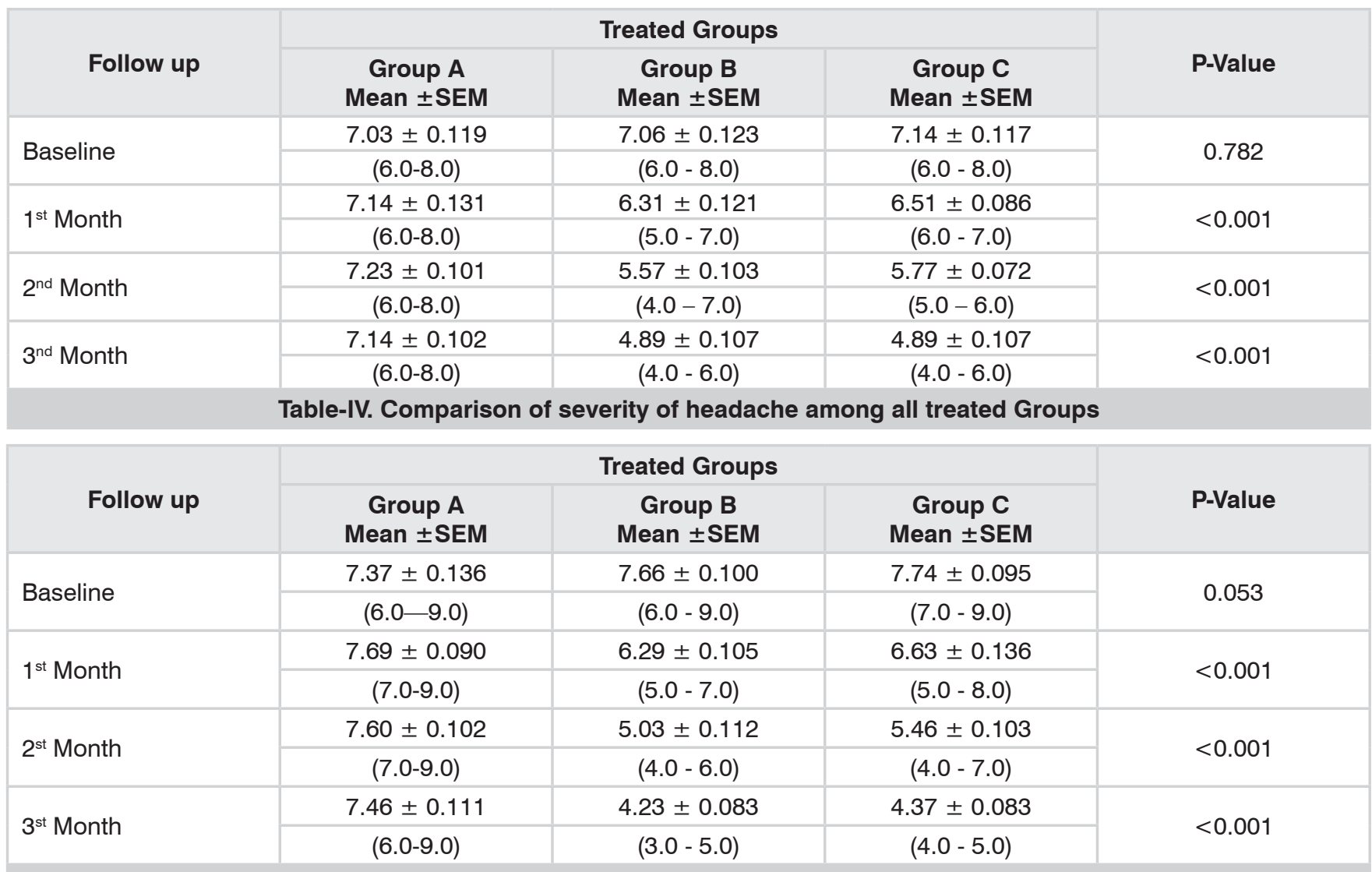

Table-V. Comparison of frequency of migraine (per Month) among all treated Groups

\section{DISCUSSION}

As indicated by the definitions set forth by the International Classification of Headache Disorder, Migraine comprises of intermittent one-sided throbbing headache of moderate to serious intensity that are bothered by physical activity. Related manifestations incorporate queasiness, spewing, and excessive touchiness to light as well as sound. Migraine Patients with headache could have aura which includes a transient visual, tangible, or other side effects previously or simultaneous with migraine. ${ }^{18}$

Pain is the most noticeable reason that Americans look for restorative consideration and the lifetime populace occurrence of perpetual pain in this nation is $33 \%$. This makes a tremendous weight on medicinal consideration frameworks and society and prompts human affliction. An imperative objective of research in the agony territory is to additionally comprehend systems driving incessant pain and create therapeutic techniques to treat pain dependent on these sub- atomic experiences.

There was proof that numerous remedial modalities don't give durable help to migraineurs raises the likelihood that the reason for the chronicity of this issue is because of certain molecular changes in the cerebrum. This may incorporate changes of explicit cortical structures including the trigeminal tactile framework and the periaqueductal gray matter (PAG), just as subatomic changes in opioidergic and dopaminergic neurons. ${ }^{19}$

In the nociceptive processes of the CNS, neuroplasticity is evident owing to harm or aggravation of peripheral tissues. ${ }^{20}$ In the trigeminal framework, neuroplasticity of caudalis nociceptive neurons might be actuated either by augmented nociceptive afferent contribution to the CNS (e.g., by direct incitement of peripheral nerves by neuropathic damage or aggravation) or by a diminished afferent information. ${ }^{21}$ Neuroplasticity might be reflected in an uplifted 
sensitivity of the focal nociceptive neurons, which might be joined by torment. It is viewed as an impression of a halfway based "practical pliancy" or "focal refinement" of the nociceptive neurons. ${ }^{22}$

Thus we will concentrate on a novel target, AMPactivated protein kinase (AMPK), which specifically targets pain promoting pathways that are associated with evolving chronic pain through the sharpening of fringe nociceptors. This objective is one of a kind among kinases under scrutiny in the torment territory since it very well may be pharmacologically focused through an "agonist" based methodology. The instrument additionally gives a novel chance to quick interpretation into the center since it tends to be locked in through actuation by clinically accessible medications, metformin and phenformin. ${ }^{23}$

Several studies demonstrate the valuable role of AMPK activation in management of different types of pain especially chronic pain, neuropathic pain associated with neuronal plasticity. Recently it was also recognizing that AMPK activation can also have clinical astonishing role in acute especially post incision pain that was refractory to other analgesics, these beneficial effects of AMPK pathway mostly due to their inhibitory effects on mTOR and MPAK pathways. ${ }^{24}$

The physiology, pharmacology and therapeutic possibilities surrounding AMPK together make it an appealing target for new action and avoidance of chronic pain. ${ }^{25}$ Metformin is the most commonly used oral anti-diabetic drug that, apart from hypoglycaemic activity, improves serum lipid profiles, has a positive effect on the haemostasis system and has anti-inflammatory activities.

Researchers have recently made attempts to establish the role of metformin in neurodegenerative disease therapy. Results from several clinical studies confirm that long-term use of metformin in patients with diabetes contributes to better cognitive function compared to respondents who use other antidiabetic drugs. ${ }^{26}$

In this study we evaluated that preventive role of Metformin in migraine patients that showed that
Metformin meritoriously improving the quality of life of migraine sufferer were evaluated by MIBS-4 (from $9.51 \pm 0.126$ to $6.46 \pm 0.085$ ), MIDS (from $23.03 \pm 0.19$ to $11.80 \pm 0.107$ ), MPQ (from 29.83 \pm 0.190 to $18.46 \pm 0.189$ ), and even decreases the Migraine frequency $(7.66 \pm 0.100$ to $4.23 \pm$ 0.083 ) and Severity of headache (from $7.06 \pm$ 0.123 to $4.89 \pm 0.107$ ). Possible mechanism of Metformin for improving the health related quality of life in migraine patient through activation of AMPK pathway which in turn inhibiting the pain promoting pathway ${ }^{27}$ and decreases the neural plasticity which is the possible mechanism of Migraine. ${ }^{28}$

\section{CONCLUSION}

This study demonstrated that Metformin meritoriously improving the health related quality of life in migraine patient. This would be valuable addition in field of preventive therapy for migraine patients.

Copyright (c) 20 Jan, 2020.

\section{REFRENCES}

1. Peter GL. Migraine overview and summary of current and emerging treatment options. Am J Manag Care. 2019; 25:S23-S34.

2. Gooch CL, Pracht E, Borenstein AR. The burden of neurological disease in the United States: A summary report and call to action. Ann Neurol. 2017; $81: 479 \square 484$.

3. Hazard E, Munakata J, Bigal ME, Rupnow MFT, Lipton RB. The burden of migraine in the United States: Current and emerging perspectives on disease management and economic analysis. Value Health. 2009; 12:55—64.

4. Gürsoy AE, Ertaş M. Prophylactic treatment of migraine. Noro Psikiyatr Ars. 2013 Aug; 50(Suppl 1):S30-S35.

5. Benemei S, Fusi C, Trevisan G, Geppetti P. The TRPA1 channel in migraine mechanism and treatment. $\mathrm{Br} J$ Pharmacol. 2014; 171(10):2552-67.

6. Obara I, Geranton SM, Hunt SP. Axonal protein synthesis: A potential target for pain relief. Curr Opin Pharmacol. 2012; 12(1):42-48. 
7. Ursini F, Russo E, Pellino G, D’Angelo S, Chiaravalloti A, De Sarro G, Manfredini R and De Giorgio R. Metformin and Autoimmunity: A "New Deal" of an Old Drug. Front. Immunol. 2018; 9:1236.

8. Anabtawi A, Miles JM. Metformin: Nonglycemic effects and potential novel indications. Endocr Pract 2016; 22(8):999-1007.

9. Anabtawi A, Miles JM. Metformin: Nonglycemic effects and potential novel indications. Endocr Pract 2016; 22(8):999-1007.

10. Price TJ, Das V, Dussor G. Adenosine monophosphateactivated protein kinase (AMPK) activators for the prevention, treatment and potential reversal of pathological pain. Curr Drug Targets. 2016; 17(8):90820.

11. Inyang KE, Szabo-Pardi T, Wentworth E, McDougal TA, Dussor G, Burton MD, Price TJ. The antidiabetic drug metformin prevents and reverses neuropathic pain and spinal cord microglial activation in male but not female mice. Pharmacol Res. 2019 Jan; 139:1-16.

12. Buse DC, Bigal MB, Rupnow M, Reed M, Serrano D, Lipton RB. Development and validation of the Migraine Interictal Burden Scale (MIBS): A self-administered instrument for measuring the burden of migraine between attacks. Neurology. 2007; 68(suppl 1):A89.

13. Buse $D$, Bigal M, Rupnow M, et al. The migraine interictal burden scale (MIBS): Results of a population-based validation study. Headache. 2007; 47(5):778.

14. Yang $M$, Rendas-Baum $R$, Varon SF, Kosinski M. Validation of the Headache Impact Test $\left(\mathrm{HIT}-6^{\mathrm{TM}}\right.$ ) across episodic and chronic migraine. Cephalalgia. 2011; 31(3):357-67.

15. Buse DC, Rupnow MF, Lipton RB. Assessing and managing all aspects of migraine: migraine attacks, migraine-related functional impairment, common comorbidities, and quality of life. Mayo Clin Proc. 2009; 84(5):422-35.

16. Silberstein SD. Preventive migraine treatment. Continuum (Minneap Minn). 2015; 21 (4 Headache):973-89.

17. D'Amico D, Tepper SJ. Prophylaxis of migraine: General principles and patient acceptance. Neuropsychiatr Dis Treat. 2008; 4(6):1155-67.
18. Ahmed F. Headache disorders: Differentiating and managing the common subtypes. $\mathrm{Br} \mathrm{J}$ Pain. 2012; 6(3):124-32.

19. Goadsby PJ, Holland PR, Martins-Oliveira M, Hoffmann J, Schankin C, Akerman S. Pathophysiology of Migraine: A disorder of sensory processing. Physiol Rev. 2017; 97(2):553-622.

20. Dubin AE, Patapoutian A. Nociceptors: The sensors of the pain pathway. J Clin Invest. 2010; 120(11):3760-72.

21. Latremoliere A, Woolf CJ. Central sensitization: A generator of pain hypersensitivity by central neural plasticity. J Pain. 2009; 10(9):895-926.

22. Woolf CJ. Central sensitization: Implications for the diagnosis and treatment of pain. Pain. 2011; 152(3 Suppl):S2-15.

23. Price TJ, Dussor G. AMPK: An emerging target for modification of injury-induced pain plasticity. Neurosci Lett. 2013; 557 Pt A:9-18.

24. Asiedu MN, Dussor G, Price TJ. Targeting AMPK for the alleviation of pathological pain. Exp Suppl. 2016; 107:257-285.

25. Megat S, Price TJ. Therapeutic opportunities for pain medicines via targeting of specific translation signaling mechanisms. Neurobiol Pain. 2018; 4:8-19.

26. Markowicz-Piasecka M, Sikora J, Szydłowska A, Skupień A, Mikiciuk-Olasik E, Huttunen KM. Metformin - a future therapy for neurodegenerative diseases: Theme: Drug Discovery, Development and Delivery in Alzheimer's Disease Guest Editor: Davide Brambilla. Pharm Res. 2017; 34(12):2614-2627.

27. Bullón P, Alcocer-Gómez E, Carrión AM, MarínAguilar F, Garrido-Maraver J, Román-Malo L, RuizCabello J, Culic O, Ryffel B, Apetoh L, Ghiringhelli F, Battino M, Sánchez-Alcazar JA, Cordero MD. AMPK phosphorylation modulates pain by activation of NLRP3 Inflammasome. Antioxid Redox Signal. 2016; 24(3):157-70.

28. Potter WB, O'Riordan KJ, Barnett D, Osting SM, Wagoner M, Burger C, Roopra A. Metabolic regulation of neuronal plasticity by the energy sensor AMPK. PLoS One. 2010; 5(2):e8996. 


\begin{tabular}{|c|c|c|c|}
\hline \multicolumn{4}{|c|}{ AUTHORSHIP AND CONTRIBUTION DECLARATION } \\
\hline Sr. \# & Author(s) Full Name & Contribution to the paper & Author(s) Signature \\
\hline 1 & $\begin{array}{l}\text { Fatima Rizvi } \\
\text { Abid Sheikh }\end{array}$ & $\begin{array}{l}\text { Designed Study, Collect data and } \\
\text { professional statistical analysis. } \\
\text { Review and proof reading of article. }\end{array}$ & \\
\hline 3 & Hira Ahmed & Proof reading of article. & \\
\hline 4 & Shazia Fahmi & Manuscript editing. & \\
\hline 5 & Zia Ikramuddin & Critical revision. & \\
\hline 6 & Mahayrukh Asif & Manuscript editing. & \\
\hline
\end{tabular}

